\title{
No Reino dos Sentidos: uma introdução ${ }^{\text {i }}$
}

\author{
Martin Jay ii
}

Tradução: Cristina Meneguello

"A ideia escandalosa de que os sentidos tem uma história, como Karl Marx uma vez observou, é um dos marcos de nossa historicidade". ${ }^{1}$ Assim escreveu o eminente crítico literário americano Fredric Jameson em 1981. Nos anos que se seguiram, talvez não tenhamos passado a ler a história em termos marxistas tal como Jameson gostaria, mas o escândalo há muito já se dissipou. Pelo contrário, explorar a infinita variedade de experiências sensórias tornou-se matéria-prima da análise histórica contemporânea, assim como dos estudos culturais e das ciências sociais de forma mais ampla. "Sentido", como cada vez mais o compreendemos, se refere não apenas aos dotes corpóreos naturais que nos permitem acessar o mundo, mas também aos significados que atribuímos aos resultados deste contato. Algumas línguas - o alemão, por exemplo, com o termo Sinn - têm palavras-chave para ilustrar esta mesma dualidade, enquanto outras, como o francês e o italiano, adicionam à palavra o significado de "direção" e "orientação", como em sens ou senso. É claro que esta complexa interação ao longo do tempo nos permite compreender que nem o sentido dos sentidos, nem o sentido produzido pelos sentidos, é invariável; tampouco funciona como a direção do fluxo de uma rua de mão única. ${ }^{2}$ De fato, conseguimos perceber ambas as mediações de tal forma que se tornou cada vez mais difícil isolar completamente um significado do outro. O significado chega em grande medida por meio dos sentidos, enquanto os sentidos

\footnotetext{
${ }^{1}$ Fredric Jameson, The Political Unconscious: Narrative as a Socially Symbolic Act (Ithaca, N.Y., 1981), 229. Nos Manuscritos Econômico-Filosóficos de 1844, Marx argumentou que os sentidos eram alienados no capitalismo - assim como a propriedade, eles eram "posses" dos indivíduos e não compartilhados comunalmente - e seriam emancipados com o fim do capitalismo. Para uma análise crítica recente da posição de Marx, ver David Howes, "HYPERESTHESIA, or, The Sensual Logic of Late Capitalism," em Howes, ed. The Empire of the Senses: The Sensual Culture Reader (Oxford, 2005), 281-303. Esta coletânea traz uma bibliografia útil dos trabalhos recentes na área de estudos culturais dos sentidos e faz parte da série da Berg Press intitulada "Sensory Formations", também editada por Howes, com coletâneas sobre os cinco sentidos assim como sobre o "sexto sentido".

20 mesmo vale para a língua portuguesa, em que a palavra "sentido" equivale à percepção sensória do mundo; à direção ou orientação; e ao significado de um termo ou palavra. NT.
} 
filtram o mundo através de significados culturais adquiridos, dentro dos quais estamos imersos. Não por outra razão os gregos podiam usar "senso comum" (koina aisthetika, que em latim tornou-se sensus communis) como um sinônimo ao mesmo tempo para a doxa, a opinião comum, e para a faculdade que permite que diferentes sentidos classifiquem um objeto singular segundo categorias universais. ${ }^{3}$

$\mathrm{Na}$ medida em que todos os humanos chegam ao mundo sem as orientações ou inclinações comportamentais que são dadas aos outros animais pelo instinto inato, necessitamos de algo que veio a ser chamado de "cultura" para compensar nossa insuficiência inerente. É o lado genial- e algumas vezes a maldição - da nossa espécie que tenhamos inventado e continuemos a inventar uma miríade de respostas para aquela demanda, uma montanha de artifícios historicamente variáveis que compensem nossa ausência de padrões de comportamento automáticos. O misto entre natureza e invenção que precisamente produz estes resultados é, evidentemente, uma fonte de disputa perene e sem fim. No caso dos sentidos, distinguir o que é dado pela natureza e o que é enfatizado - ou abrandado - pela cultura é especialmente desafiador. É bem provável que a relativa lentidão com a qual desenvolvemos as histórias dos sentidos não se deva apenas à natureza "escandalosa" da proposta, mas também à sua dificuldade genuína, especialmente se reconhecermos que a evidência para a mudança é geralmente enganosa, contraditória e de representatividade dúbia. ${ }^{4}$ Mas, por razões que são sem dúvida históricas, tornamo-nos cada vez mais dispostos a encarar este desafio.

Podemos apenas conjecturar quais fatores precisos levaram ao crescimento dos estudos históricos dos sentidos. Várias "viradas" (turns) cultural, linguística e do corpo- abriram novos e até então inexplorados territórios do passado que permitiram um exame mais aprofundado de um

\footnotetext{
${ }^{3}$ Para a história do termo, ver John D. Schaeffer, Sensus Communis: Vico, Rethoric, and the Limits of Relativism (Durham, N.C., 1990). Para um estudo recente da origem do termo em Aristóteles, ver Pavel Gregoric, Aristotle on the Common Sense (Oxford, 2007).

4 Para uma análise sóbria destas dificuldades, por um dos mais completos estudiosos da história dos sentidos, ver Alain Corbin, "Charting the Cultural History of the Senses", in Howes, The Empire of the Senses, 128-139.
} 
fenômeno antes ignorado. ${ }^{5}$ A inexorável pressão por uma maior inclusão dos estudos da vida cotidiana, um crescente reconhecimento da dignidade da pequena história (petit histoire), e o resgate dos temas "de baixo" de qualquer tipo, todos conspiraram para nos alertar para a importância das transformações históricas da experiência dos sentidos. O crescente interesse nos sentidos nas disciplinas auxiliares como a antropologia, a sociologia e a crítica literária, todas vieram manifestar-se nos estudos históricos. ${ }^{6}$ Uma geração formada pelas investigações arqueológicas e genealógicas de Michel Foucault sobre a disciplina do corpo e o cuidado de si encontrou inspiração ao recuperar antigos estudos sobre a dimensão corpórea do "processo civilizatório" realizados por sociólogos como Norbert Elias. ${ }^{7}$

Na cena artística contemporânea, o que foi chamado de "desestetização do estético" também centrou sua atenção na dialética da sublimação e des-sublimação do corpo na prática artística e a na intersecção entre a "alta" arte e seu contexto cultural mais amplo. Chamouse para a arena a divisão longeva entre as artes de acordo com seu registro sensorial dominante, tabu poderoso desde Gotthold Ephraim Lessing até

\footnotetext{
${ }^{5}$ A relevância da "virada linguística" para o novo interesse pelos sentidos pode parecer menos óbvia que as outras duas. Entretanto, foi ela que abriu a questão para as metáforas sensoriais incrustradas na linguagem, que nos alertou para a importância dos vetores materiais e sensórios para convir os significados e que explorou as questões da tradutibilidade - ou de sua impossibilidade - entre as linguagens convencionais, faladas ou escritas e as "linguagens" das imagens, dos sons, dos odores, dos sabores e dos toques. 0 desenvolvimento histórico dos sotaques, com todas as suas poderosas implicações culturais, mostra a importância do som na compreensão da linguagem. Ver, por exemplo, os ensaios em Talking and Listening in the Age of Modernity: Essays in the History of Sound, Joy Damousi e Desley Deacon (eds), (Canberra, 2007). Certamente houve resistência a assimilar os sentidos a um modelo linguístico. Por exemplo, Michel Serres, The Five Senses: a Philosophy of Mingled Bodies, trad. Margaret Sankey e Peter Cowley (New York, 2009).

6 Ver, por exemplo, o periódico The Senses and Society, lançado em 2006. A institucionalização dos estudos de cultura visual, os mais avançados se comparados aos estudos voltados aos outros sentidos, é traçada por Margaret Dikovitskaya em Visual Culture: the Study of the Visual after the Cultural Turn (Cambridge, Mass., 2005). Observese que dentre as 17 entrevistas que ela realiza com as figuras centrais naquela área, anexas ao livro, apenas um dos entrevistados ensina em um departamento de história.

7 Ver, por exemplo, os ensaios de Jan Goldstein, ed. Foucault and the Writing of History (Cambridge, Mass, 1994). O agora familiar argumento de Foucault sobre as relações entre o poder e o olhar exemplificados pelo Panóptico de Jeremy Bentham já foi, porém, desafiado. Ver Chris Otter, The Victorian Eye: A Political History of Light and Vision in Britains, 18001910 (Chicago, 2008). Para uma seleção de reações a Elias, ver Steven Loyal and Sthephen Quilley, The Sociology of Norbert Elias (Cambridge, 2004).
} 
Clement Greenberg. ${ }^{8}$ A emergência das questões ecológicas ou ambientais e a ressentida consciência do papel destrutivo que o homem tem dentro da biosfera também tiveram seu impacto. Até mesmo a filosofia, que tão frequentemente mostra-se hostil aos apelos básicos do corpo em seu intento de privilegiar a mente, começou a dar-se conta do tema, mudança esta registrada de forma irreverente por Jacques Derrida com sua infame pergunta em seu livro sobre Hegel e Genet, Glas: "como pode a ontologia apossar-se de um peido?" 9 A mesma curiosidade hoje com frequência alimenta os estudos religiosos, que vão bem além das ansiedades tradicionais com os assim chamados "pecados da carne". ${ }^{10}$

Se os sentidos podem situar-se nas instáveis encruzilhadas entre a natureza e a cultura, eles também são lugares exemplares para se explorar oposições perenes, tais como a agência subjetiva e a determinação objetiva, a arte e a ciência, a agência e a passividade ${ }^{11}$, apenas para mencionar alguns ${ }^{12}$. Os sentidos funcionam não apenas como portadores de informação vital sobre o mundo, abrindo-nos para os estímulos de fora, mas agem como guardiões de nossa integridade, protegendo-nos dos perigos e ameaças externos. Mais do que fontes de conhecimento, direção e significado, eles servem também como avenidas para o prazer e para a dor, cujos limites podem variar em termos culturais ou individuais. Ao mesmo tempo em que os sentidos nos humilham em comparação com os animais, cuja visão é mais aguda, a audição mais poderosa e o olfato mais desenvolvido, eles nos engrandecem ao demonstrar que somos a única

\footnotetext{
${ }^{8}$ A questão da relação entre "Arte" e as artes é explorada por Jean-Luc Nancy, The Muses, trad. Peggy Kamuf (Stanford, Calif., 1996). Ele nos relembra que "a arte leva o sentido a tocar a si próprio, a ser o sentido em si. Mas, desta maneira, ela não se torna simplesmente o que chamamos de 'um sentido', por exemplo, a visão ou a audição: ao deixar para trás a integração do 'vivido', ela se transforma em algo diverso, em outra instância de unidade, e expõe outro mundo: não um mundo 'visual' ou 'sonoro', mas um mundo 'pictórico' ou 'musical'"' (21).

9 Jacques Derrida, Glas (Paris, 1974), 69.

10 Ver, por exemplo, Birgit Meyer, ed., Aesthetic Formations: Media, Religion, and the Senses (Basingstoke, 2009).

${ }^{11}$ Nossa língua captura de forma rica a ambivalência da agência e da passividade nos duplos sentidos dos verbos "cheirar" [to smell], "olhar"[to look], "saborear" [to taste] e "sentir" [to feel]. Nosso ouvir não tem um verbo assim, ao mesmo tempo ativo e passivo. Pelo contrário, ele tem"eu ouço" [I hear] e "eu escuto" [I listen] e"eu sôo" [I sound].

${ }^{12} \mathrm{O}$ que $\mathrm{o}$ autor observa aqui são os verbos na língua inglesa que ao mesmo tempo indicam agência e passividade. Por exemplo, na língua portuguesa seria o caso do verbo cheirar: ao mesmo tempo uma fruta passivamente "cheira" (tem aroma) e uma pessoa cheira a fruta (agência). NT.
} 
espécie que de forma deliberada pode desenvolver e ampliar os potenciais que nos foram dados pela natureza. Fixando-nos de forma temporal no aqui e no agora, onde estamos sujeitos a estímulos variáveis e constantes, não obstante os sentidos podem despertar as nossas memórias, voluntárias e involuntárias. Entendidos de forma experimental, os sentidos possuem qualidades que exigem todos os recursos da linguagem para comunicar o seu poder, e mesmo assim geralmente permanecem indescritivelmente pessoais. Quem, afinal, se lançaria a descrever o perfume de uma rosa em vez de a rosa em si? Entendidos de forma científica, os sentidos revelam alguns dos segredos do pesquisador objetivo procurando respostas dentro da fisiologia comum das espécies. Unir as perspectivas experimentais e científicas nunca foi tarefa simples; nenhuma tertium comparationis ${ }^{13}$ foi ainda encontrada para que se possa traduzir o Cântico dos Cânticos nos termos da neurociência ou da psicologia cognitiva.

No entanto, o que nos interessa aqui são os sentidos compreendidos historicamente. Um número de questões fundamentais tem guiado a pesquisa realizada pelos historiadores dos sentidos. Como o sensório foi, de forma geral, diferenciado discursivamente em diversos contextos? Todas as culturas postularam os mesmos cinco sentidos, ou outros foram incluídos? Se, como afirmaram alguns cientistas, não há nada menos do que dezessete modos pelos quais os animais sentem o mundo de fato, algum sentido além dos canônicos cinco foi atribuído aos humanos? ${ }^{14}$ Quando supostos sextos-sentidos tais como o equilíbrio, o desejo ou o discurso foram adicionados ao conjunto? Como foram compreendidos os papéis da percepção espacial do próprio corpo [proprioception] ou o sentido cinestésico? Existe um primeiro "sentido interno" [inner touch $]^{15}$ que nos diz que somos criaturas conscientes, e, se existe, tem ele uma história? ${ }^{16}$ Existe a percepção "extra-sensorial", ou, para usar termos históricos, quais

\footnotetext{
13 Tertium comparationis: a presença de ao menos uma qualidade em comum entre duas coisas que estão sendo comparadas. NT.

${ }_{14}$ Robert Rivlin and Karen Gravelle, Deciphering the Senses: The Expanding World of Human Perception (New York, 1984). Os exemplos incluem a localização por eco dos morcegos, a orientação bussolar dos pássaros em migração e os impulsos elétricos dos tubarões.

${ }^{15}$ Inner Touch é o sentido interno, diferente dos outros cinco sentidos e que, segundo Aristóteles (Tratado Da Alma), permite a um ser sentir que ele está sentindo. NT.

16 Para uma sugestiva tentativa de um filósofo de traçar este percurso, ver Daniel HellerRoazen, The Inner Touch: Archaelogy of a Sensation (New York, 2009).
} 
as tentativas já realizadas para identificar a percepção extra-sensorial, e como estas foram encaradas?

Todas as culturas classificaram os sentidos de forma hierárquica - da maneira como a maior parte dos autores ocidentais fez desde os gregos com os sentidos da visão e da audição supostamente "mais nobres" que os outros três? Outras culturas desenvolveram diferentes hierarquias, talvez experimentais assim como discursivas, e foram elas historicamente modificadas? A diferenciação e o desenvolvimento desigual dos sentidos, não importa como postulados, são dados pela natureza ou o produto das forças históricas? Quando, se é que ocorre, o prevalente "ocularcentrismo" de tantas culturas vai ceder privilégio e espaço aos outros sentidos? ${ }^{17}$ É possível localizar culturas "audiocêntricas" ou "tatocêntricas", ou mesmo "gastrocêntricas" ou "olfatocêntricas"? Alguma vez o processo de diferenciação e classificação foi revertido para que uma diferenciação intersensorial pudesse ocorrer? A sinestesia - a integração harmônica dos sentidos - é um paraíso real ou uma mera fantasia da imaginação poética?

De que formas a cultura desenvolveu tecnologias para estender e ampliar os sentidos, criando uma gama de apetrechos exossomáticos que compensem os limites de nossa natureza? Para além de exemplos óbvios, como a armadura ou a anestesia que protegem nosso vulnerável sentido de tato, os telescópios e os microscópios que ampliam o nosso alcance visual, os aparelhos de audição que detectam frequências sonoras que nossos ouvidos não podem registrar ou os microfones que ampliam o volume de nossas vozes, quais outros aparelhos protéticos transformaram as nossas capacidades naturais? De que modos a relação entre a temporalidade e o sensório foi afetada pela invenção de aparelhos - considerando até mesmo a invenção da própria linguagem escrita - de forma a amparar, transmitir e reproduzir as experiências sensoriais, dos fixadores químicos para os perfumistas às câmeras digitais e gravadores que transformaram as paisagens sensórias visuais e aurais do mundo moderno? Alguns sentidos

\footnotetext{
17 A audição é sempre a alternativa escolhida. Ver, por exemplo, os papers do 90 Colóquio Blankensee sobre a história moderna da audição: "Hearing Modern History: Auditory Cultures in the 19th and 20th Century," http://www.geschkult.fuberlin.de/e/fmi/arbeitsbereiche/ab_nolte/dokumente/Morat/blankensee.html
} 
foram afetados mais que outros por estas extensões tecnológicas de forma a permitir, por exemplo, uma distinção mais explícita entre natureza e cultura, tal como a indicada pelo conhecido contraste entre "visão e visualidade" ${ }^{18} \mathrm{E}$ o que dizer daquelas técnicas e invenções voltadas a embotar os sentidos, ou até mesmo a suspender temporariamente seus efeitos, desde as práticas ascéticas dos faquires que podem andar sobre carvões em brasa até os milagres da moderna anestesia médica? É possível desassociar os dados de sentido do universo sensório humano real, conduzindo a um reino de experiência sensória impessoal, recentemente chamado de "cultura do diagrama?". ${ }^{19}$

Como, historicamente, a perda ou diminuição dos sentidos foi compreendida, lamentada ou relevada? Está correto o romancista britânico David Lodge quando afirma que "a surdez é cômica e a cegueira, trágica?" 20 A rubrica "estudos de deficiências" [disability studies] é a melhor categoria para interpretar reações à privação ou modificação sensória? ${ }^{21}$. Poderia a perda de um sentido aumentar a acuidade de outro, dessa forma paradoxalmente produzindo uma nova "habilidade" ${ }^{22}$ Como pensar as reivindicações por uma "cultura surda", apartada mas não inferior, e que gerou uma extensa literatura própria, parte dela histórica? ${ }^{23}$ Como podemos compreender a relação entre a eliminação deliberada das experiências sensórias coletivas - os odores fétidos da vida tradicional que foram erradicados em nome da higiene - e as condição fisiológica da perda

18 Esta distinção tornou-se conhecida com a publicação de Hal Foster (ed.), Vision and Visuality (Seattle, 1988), mas pode ser recuada até Thomas Carlyle em 1841. Ver Nicholas Mirzoeff, "On Visuality," Journal of Visual Culture 5, n.1 (April, 2006): 53-79.

19 John Bender e Michael Marrinan, The Culture of Diagram (Stanford, Calif., 2010). Eles argumentam que os diagramas são "dados visuais" que transcendem a experiência dos olhos reais olhando para o mundo ou representando o mundo em termos miméticos. Iniciando no século XVIII, com a Encyclopédie Francesa, os autores mostram que os diagramas trilharam um caminho próprio em relação a diferentes práticas modernas, tanto científicas e artísticas quanto tecnológicas.

${ }^{20}$ David Lodge, Deaf Sentence (London, 2008), 13.

21 Para uma exploração da relação entre os estudos de deficiência e a visualidade, ver Disability and Visuality, Special Issue, Journal of Visual Culture 5, n.2 (Agosto 2006)

${ }^{22}$ Helen Keller era admirada por sua extrema sensibilidade olfativa; ela sabia que uma tempestade se aproximava pela alteração nos aromas. Ver Diane Ackermann, A Natural History of the Senses (New York, 1991), 44.

${ }^{23}$ Para vários exemplos, ver as publicações da Gallaudet University Press, como Deaf History Unveiled: Interpretations from the New Scholarship de John Vickrey Van Cleve (ed.), (Washington, D.C. 1999); The Deaf History Reader, Van Cleve (ed.) (Washington. D.C, 2007); e de Benjamin Fraser (ed.) Deaf History and Culture on Spain: a Reader of Primary Sources (Wasington, D.C., 2010). 
de olfato individual que os cientistas denominam de anosmia? Ocorreram danos radicais - ou talvez melhor dito, ocorreu a desvalorização dos sentidos - em certas culturas, como provocativamente foi argumentando por Theodor W. Adorno para o caso da "regressão da audição" das audiências musicais modernas ${ }^{24}$ A estimulação artificial, a manipulação e até o desarranjo dos sentidos são um tema a ser estudado em um capitalismo tardio que opera por meio da implacável instigação de novas demandas de consumo?

Como podemos periodizar de forma plausível, e narrar as mudanças do sensorial em diferentes contextos? Os períodos que estabelecemos podem ser aplicados a outros períodos familiares a nós por sua história política, econômica, tecnológica ou social, ou eles seguem seus próprios desenvolvimentos internos? Conforme amadureceu o campo da história dos sentidos, as generalizações mais amplas e em bloco sobre épocas inteiras perderam em plausibilidade? Qual é a relação entre as suposições culturais hegemônicas sobre os sentidos - a mentalidade [mentalité] sensória de um período - e as práticas reais, materiais e corpóreas de uma era, que podem se alterar segundo diferenças sociais, econômicas e de gênero? Mesmo as tentativas para delinear de forma mais modesta e circunscrita os "regimes de escuta ou regimes escópicos" 25 tiveram que encarar as críticas de que falharam em reconhecer as evidências que desafiam a sua suposta homogeneidade ${ }^{26}$. De forma similar, grandes narrativas nas quais um sentido dominante é substituído por outro, em um deslizamento histórico, são cada vez mais chamadas à cena. Se, por exemplo, Sigmund Freud

\footnotetext{
${ }^{24}$ Theodor W. Adorno, "On the Fetish-Character in Music and the Regression of Listening" [Fetichismo na Música e Regressão da Audição]. Adorno, Essays on Music, seleção, com introdução, comentários e notas de Richard Leppert, Susal H. Gillespie (trad.) (Berkeley, Calif., 2002), 288-317.

${ }^{25}$ O termo "regime escópico" foi introduzido pelo crítico de cinema francês Christian Metz e utilizado de forma mais ampla por Martin Jay em "Scopic Regimes of Modernity", pela primeira vez publicado em Foster, Vision and Visuality, 3-27. Seu equivalente para a audição é desenvolvido por Peter Szendy em Listen: a History of Our Ears, Charlotte Mandel (trad.), (New York, 2008).

${ }^{26}$ Martin Jay utiliza a expressão "regime escópico" que retira de O Significante Imaginário Psicanálise e Cinema de Christian Metz, cuja obra apontou, ao distinguir o cinema do teatro, uma espécie de contexto cultural para a visão, ou seja, a existência de tecnologias do olhar segundo momentos históricos particulares. Para Jay, na modernidade há três subculturas visuais dentro do regime escópico: a perspectiva cartesiana - nos moldes do Renascimento italiano; a Arte da Descrição - que associa, assim como Svetlana Alpers, à pintura setecentista dos Países Baixos; e o Barroco. NT.
} 
estava certo ao argumentar em uma célebre nota de rodapé de Civilização e seus Descontentes que, com a adoção da postura ereta, os hominídeos abandonaram a prioridade da estimulação olfativa em benefício da visual, então por que razão tal substituição teve de ocorrer novamente na aurora da era moderna? ${ }^{27}$

Como resultado destas questões e receios, narrativas mais gerais e populares como A Natural History os Senses de Diane Ackerman (1991), uma obra impressionista, rapsódica e que mistura ciência, folclore e experiências pessoais - foram suplantadas por tratados mais sóbrios e sistemáticos, como A History of the Senses de Robert Jütte (2005). ${ }^{28}$ Muitas das afirmações globais sobre a distribuição dos sentidos em culturas e períodos específicos, feitas pelos pioneiros dos estúdios de mídia como Marshall McLuhan ou Walter Ong nos parecem datadas; vale o mesmo para o trabalho de historiadores como Lucien Febvre e Robert Mandrou. Além disso, uma onda de estudos específicos sobre cada sentido em particular, geralmente com o apoio de uma rede de periódicos, conferências e cursos universitários, criaram crescentes tradições discursivas, mesmo que incipientes. Ainda que dividida de forma desigual, com alguns sentidos ganhando a "parte do leão" da atenção geral, e muitas vezes hermeticamente fechada para qualquer trabalho realizado fora de sua estreita área de atuação, a história dos sentidos - podemos hoje dizer - é bem menos um escândalo e muito mais uma empreitada vigorosa e dominante, com um futuro brilhante à sua frente.

\footnotetext{
' Somos gratos à The University of Chicago Press (Chicago Journals) e à American Historical Association que nos autorizaram a traduzir e publicar este texto de Martin Jay, originalmente publicado na The American Historical Review, vol 116. N. 2, abril de 2011, cujo tema foi Os Sentidos na História (The Senses in History). Optamos por traduzir a parte do texto em que Martin Jay analisa de forma geral a "história da história dos sentidos", lançando uma série de questões ao leitor. A parte final do texto não foi aqui incluída, pois é a breve apresentação de cada um dos artigos que compõe o volume da The American Historical Review mencionado, e só faz sentido naquele contexto.
}

\footnotetext{
${ }^{27}$ Sigmund Freud, Civilization and Its Discontents, James Strachey (trad. e ed.) (New York, 1961). 46-47. Para um exemplo da afirmação de que a modernidade significou o triunfo do visual, ver Lucian Febvre, The Problem of Unbelief in the Sixteenth Century: The Religion of Rabelais [O problema da incredulidade no século XVI - a religião de Rabelais], trad. Beatrice Gottlieb (Cambridge, Mass., 1982), 432.

${ }^{28}$ Aclkermann, A Natural History of the Senses; Robert Jütte, A History of the Senses: from Antiquity to Cyberspace (Malden, Mass., 2005).
} 
ii Martin Jay (1944), especialista em história intelectual e em teoria crítica, é professor de história da Universidade da California, Berkeley (cátedra Sidney Hellman Ehrman). Dentre seus trabalhos destacamos Imaginação Dialética (publicada originalmente em inglês em 1973 e publicada no Brasil pela Editora Contraponto em 2008); Marxism and Totality (University of California Press, 1984); Adorno (Harvard University Press, 1984); Permanent Exiles (Columbia University Press, 1985); Fin-de-Siècle Socialism (Routledge, 1989); Force Fields (Routledge, 1993); Downcast Eyes (University of Califormia Press, 1993); Cultural Semantics (University of Massachusetts Press, 1998); Refractions of Violence (Routledge, 2003); Songs of Experience (University of California Press, 2004); The Virtues of Mendacity (University of Virginia Press, 2010); Essays from the Edge (University of Virginia Press, 2011). 